\title{
Sleeve video-assisted thoracic surgery resections
}

\author{
Davide Tosi, Valeria Musso, Francesco Damarco, Shehab Mohamed, Alessandra Mazzucco, \\ Margherita Cattaneo, Elisa Daffrè, Cristina Diotti, Sara Pieropan, Mario Nosotti
}

Thoracic Surgery and Lung Transplantation Unit, Fondazione IRCCS Ca' Granda Ospedale Maggiore Policlinico, Milan, Italy Contributions: (I) Conception and design: D Tosi; (II) Administrative support: D Tosi; (III) Provision of study materials or patients: D Tosi, V Musso, F Damarco, S Mohamed; (IV) Collection and assembly of data: D Tosi, V Musso, F Damarco, S Mohamed; (V) Data analysis and interpretation: D Tosi, V Musso, F Damarco, S Mohamed; (VI) Manuscript writing: All authors; (VII) Final approval of manuscript: All authors.

Correspondence to: Davide Tosi, MD. Thoracic Surgery and Lung Transplantation Unit, Fondazione IRCCS Ca' Granda Ospedale Maggiore Policlinico, 20122 Milan, Italy. Email: davide.tosi@policlinico.mi.it.

\begin{abstract}
Since the first bronchial sleeve resection was performed in 1947, these types of procedures have gradually taken on a greater role over the years, in order to preserve lung function in patients with centrally located tumors. Patient selection and pre-operative assessment are crucial, as the intra-operative strategy may be modified during surgery. Intraoperative conduct involves essential steps, such as frozen sections analysis on both proximal and distal margins, to ensure oncological adequacy. Several studies reported oncological outcomes after sleeve resections comparable to pneumonectomy, with lower postoperative mortality and morbidity. Sleeve lobectomy is now considered the procedure of choice for anatomically suitable lesions, regardless of pulmonary function, but is still considered a challenging and technically demanding procedure, especially when carried out by video-assisted thoracic surgery (VATS) approach. In the last 10 years, the number of reported VATS sleeve resections has exponentially increased. Several studies have compared the outcomes of patients undergoing sleeve resections, by open vs VATS technique, reporting similar rates of harvested lymph node and recurrence between the two groups; patients in the VATS group showed less blood loss and a shorter hospital length of stay. The aim of this review article is to describe indications, technical aspects and outcomes of VATS sleeve resections.
\end{abstract}

Keywords: Sleeve lobectomy; bronchial anastomosis; video-assisted thoracic surgery (VATS); non-small cell lung cancer (NSCLC)

Received: 01 December 2019; Accepted: 12 December 2019; Published: 25 May 2020.

doi: $10.21037 /$ ccts.2019.12.10

View this article at: http://dx.doi.org/10.21037/ccts.2019.12.10

\section{Introduction}

Surgical treatment of locally advanced and centrally located non-small cell lung cancer (NSCLC) is based on the principle of parenchyma preservation, if technically feasible. In this context, the use of lung resections with bronchoplastic techniques plays an important role, in order to preserve lung function. The first documented bronchial sleeve resection was performed in 1947 by Thomas for a patient with pulmonary carcinoid located in the right mainstem bronchus (1). In 1952, Allison performed the first successful right upper lobe sleeve lobectomy for a patient with bronchogenic carcinoma (2). In 1950, Abbott reported four cases of right pneumonectomy with en bloc excision of the carina, lateral wall of the trachea and part of the left main bronchus (3). In 1959, Chamberlain and colleagues reported the first case of sleeve pneumonectomy (SP) (4). In 1982, Grillo published his experience on carinal resection in 36 patients and presented a comprehensive schema for carinal reconstruction (5). In 2002, Santambrogio and colleagues reported the world's first full videoassisted thoracic surgery (VATS) sleeve lobectomy with bronchoplasty on a 15 -year-old female with lowgrade mucoepidermoid carcinoma of the left lower lobe bronchus (6). With the development of VATS technology and increased experience of surgeons using minimally 
Table 1 Exams indicated for pre-operative evaluation

Physical examination
Hematochemical analysis
Pulmonary function
Basal and stress spirometry (PFTs)
DLCO
Arterial blood gas analysis
Cardiac function
Cardiologic evaluation
Electrocardiography
Transthoracic echocardiography
Cardiopulmonary exercise testing
Imaging
Chest X-ray
Chest, upper abdomen CT
Brain MRI in selected cases
PET
Perfusion scan

Bronchoscopy with biopsies to evaluate the extent of airway involvement

EBUS/mediastinoscopy to assess mediastinal lymph nodes

PFTs, pulmonary function tests; DLCO, diffusing capacity of the lung for carbon-monoxide; CT, computed tomography; $\mathrm{MRI}$, magnetic resonance imaging; PET, positron emission tomography; EBUS, endobronchial ultrasound.

invasive approach, the number of cases of sleeve lobectomy performed by VATS has increased. Surgeons have been skeptical to adopt and develop this technique because of oncological concerns and highly surgical skills required. After two decades of development since Santambrogio's first reported case, VATS sleeve lobectomy has become a routine operation in high-experience centers, even performed by uniportal VATS (7). Some extended procedures, such as thoracoscopic double sleeve lobectomy $(8,9)$ and carinal resections have been reported (10). The aim of this review article is to describe actual features of VATS sleeve procedures.

\section{Indications}

Sleeve lobectomy for lung cancer was initially proposed as an alternative to pneumonectomy for patients with poor cardiopulmonary reserve. Although this indication is still solid, sleeve resections should also be considered in any situation that is anatomically favorable for the treatment of centrally located tumors. In experienced centers, indications to sleeve VATS procedures do not differ from open procedures (11-14).

Nowadays routinely indications for sleeve resection are:

* Primary tumor located at the origin of a lobar bronchus;

* Primary tumor located at the origin of a lobar branch of the pulmonary artery;

* Findings of a positive bronchial margin after a standard lobectomy;

* Peripheral tumors with nodal involvement infiltrating the origin of the lobar bronchus or a lobar branch of the pulmonary artery;

* Stenosis caused by infectious diseases (e.g., tuberculosis) or post-traumatic.

The main malignant indication requiring sleeve resection is NSCLC (squamous cell carcinoma and adenocarcinomas). Other common causes are carcinoids, hamartomas and adenoid cystic carcinomas or mucoepidermoid tumors. Any lobe can be a potential site for sleeve resection but the most common is the right upper lobe, also because of the relative length of the bronchus intermedius and the favorable arterial anatomy (15-17).

\section{Patient selection and preoperative evaluation}

Despite sleeve lobectomy being the proposed procedure, operative findings may sometimes dictate the necessity of pneumonectomy; therefore, every patient must be evaluated for the most extended procedure. Preoperative evaluation provides careful clinical assessment, determination of the extension of lesion and resection, estimation of cardiopulmonary reserve and potential nodal involvement (Table 1). The assessment always includes computed tomographic (CT) scans in order to evaluate the infiltration of the bronchial structures. Bronchoscopy can confirm endobronchial involvement and allows to perform preoperative biopsies. Magnetic resonance imaging (MRI) and positron emission tomography (PET) scan contribute to estimate the extent of infiltration and the possibility of distant metastases, including the nodal status. If nodal involvement is suspected, an assessment with mediastinoscopy or endobronchial ultrasound (EBUS) is required. It is recommended to perform mediastinoscopy prior to sleeve resection under the same anesthesia to avoid fibrosis and 
fixation around the proximal main bronchi due to mediastinal procedure. This can also facilitate the subsequent dissection of the bronchi during sleeve resection. Perfusion scans may be required to assess the expected loss of pulmonary function after resection and it is mandatory in the event of pneumonectomy. In any case it can be difficult to establish preoperatively an indication for sleeve reconstruction, so the last evaluation will be necessarily surgical: in this scenario, we stress that the patient must be evaluated also for pneumonectomy $(12,18-22)$.

\section{Contraindications}

Patients with advanced lung disease or depressed cardiopulmonary reserve are poor candidates for sleeve lobectomy. Namely, contraindications include unresectable or metastatic disease. Also, the invasion of the phrenic nerve, the vagus nerve and the diaphragm is considered a contraindication to sleeve lobectomy, while the invasion of the main pulmonary artery is a relative contraindication. The procedure should not be performed in patient with inadequate pulmonary reserve or impaired cardiac function (23). In the first published articles, neoadjuvant therapy ( $>45$ Gy) or steroid use were considered relative contraindications because of the risk of fibrosis or anastomotic dehiscence, but many authors demonstrated similar mortality and incidence of airway complications between treated and non-treated patients $(24,25)$. N2 nodal disease is not an absolute contraindication, but it significantly impairs long-term outcomes due to local (40\%) and distant $(21 \%)$ recurrences $(26,27)$. The situation for N1 disease remains controversial. Some authors demonstrated a significant difference in survival between $\mathrm{N} 1$ and N2 diseases but not between $\mathrm{N} 0$ and $\mathrm{N} 1(17,28,29)$.

\section{Surgical technique}

Dealing with VATS sleeve lobectomy, we must comply with oncological, general and basic principles of bronchial reconstruction. It is mandatory to ensure free of disease resection margins and an adequate vascularization of a tension-free anastomosis. The procedure is conducted in general anesthesia with a double lumen tube, even though non intubated sleeve resections have been reported (30). The procedure can be performed by multiportal or uniportal technique, depending on surgeon's attitude $(7,31)$. The site of incision can be the fifth or fourth intercostal space; in our opinion, the fourth intercostal space is the best choice, particularly for upper lobectomies, because it guarantees a closer access to the bronchial anastomosis. The first step of the operation is the release of the inferior pulmonary ligament and the division of the mediastinal pleura around the hilum. The mediastinal lymph-node dissection is conducted before the bronchotomy, in order to further release the tension. Some Authors suggest a hilar release by cutting the pericardium around the inferior pulmonary vein in cases of high-tension anastomosis; we believe that this is not mandatory in case of "standard" sleeve resections, but it can be useful when performing "extended" sleeve lobectomies (32). In all types of sleeve lobectomies, pulmonary arteries and veins are transected prior to bronchotomy; also, the fissure is usually divided before bluntly dissecting the peribronchial tissue. The cutting section of the bronchus is guided by endoscopic evaluation; in case of disease located at the origin of the main bronchus, it is advisable to lift the trachea with a stitch, in order to avoid retraction into the mediastinum after bronchotomy. Frozen sections analysis on both proximal and distal margins are mandatory, to ensure that both are free from disease. In case of discrepancy between proximal and distal bronchial stump, it is important to adjust the calibre before starting the suture. Reconstruction is the key point in this kind of procedures: it can be technically demanding because of the limited working space. The choice of the type of suture material depends on surgeon's preference: most Authors believe that a monofilament is recommended, while there is no unanimity on the use of a readsorbable or non-readsorbable suture. A silk suture is contraindicated because of the risk of granulation that can lead to a bronchial stenosis (33). In our experience, a $4 / 0$ readsorbable monofilament is the preferred material. The way of VATS suturing is different, compared to open sleeve lobectomy: it is better to avoid interrupted suture of the cartilaginous pars, and to choose a technique with one single running suture for the whole end-to-end anastomosis or two separate threads, especially for left sided upper lobe sleeves $(34,35)$. Usually, after confirming the absence of an air leak from the anastomosis by inflating the lungs in presence of saline solution, an intraoperative bronchoscopy is performed. An anastomosis coverage can be indicated, particularly after chemoradiation or in case of extended sleeve lobectomies. Different tissues can be utilized: the azygos pedicled flap in the right side, a pedicled aortic adventitia flap (36), the pericardial fat tissue or the intercostal muscle flap, which is easy to perform, even in VATS procedures (37). Berthet et al. reported a 
routine use of the intercostal muscle flap, Toyooka et al. usually used pericardial fat tissue or greater omentum for anastomosis covering $(38,39)$. Other authors did not perform anastomosis coverage routinely, while Okada, Yamamoto, and Chida created coverage with fat tissue or muscle only in cases with combined angioplasty to separate the two anastomotic sites, thus preventing bronchovascular fistulae $(32,40,41)$.

\section{Oncological and functional outcomes}

In a retrospective study published in 2005, Ludwig reviewed the outcomes of 310 patients with lung cancer up to stage IIIA who underwent pneumonectomy or sleeve lobectomy. In this study radicality was obtained in $98 \%$ of patients; 5 -year overall survival after sleeve resection was $39 \%$ and $27 \%$ after pneumonectomy, but it should be noted that survival was shown to be influenced by the age of the patients, lymph node status and disease stage. The Authors concluded that sleeve lobectomy was superior to pneumonectomy with regard to long-term survival, as there were no differences in short-term survival between the two groups (29). Okada et al. particularly focused on lymph-node involvement in a work published in 2000 which compared pneumonectomy with sleeve resection using nearest available matching method. The results showed that sleeve lobectomy had a better survival rate at 3,5 and 10 years. Notably, nodal status resulted the most important factor affecting survival, and the Authors suggested that sleeve resection should be the procedure of choice whenever the complete excision of the lesion can be reached (42). The superiority of sleeve lobectomy over pneumonectomy in terms of both survival and postoperative pulmonary function was also asserted by Park et al., who compared sleeve lobectomies to pneumonectomies with a propensity score match analysis that showed a lower operative mortality and better overall 3- and 5-year survival rates after sleeve lobectomy; also, there was no significant difference in the pattern of recurrence between the two groups. When comparing the predicted post-pneumonectomy FEV1 with the actual post-operative FEV1 of patients who underwent sleeve resection, the authors found an increase by $7.9 \%$ of this value (43). In 2017, Pagès et al. published the data on sleeve lobectomy and pneumonectomy recorded in the Epithor French database. Analyses of this national clinical database, carried out using both propensity score and inverse probability of treatment weighting, showed a similar postoperative mortality between the two groups, even though postoperative complications were more frequent following sleeve lobectomy. Data on overall and diseasefree survival were controversial, as an augmented risk of death and recurrence was found in the pneumonectomy group only when using matching analysis (44). A metaanalysis was published by Shi et al. in 2012 in order to determine whether sleeve lobectomy was to be preferred to pneumonectomy in patients with NSCLC: this work included 19 articles with a combined total of 1,316 sleeve lobectomies and 2,562 pneumonectomies. The Authors reported no statistically significant differences in terms of post-operative complications or locoregional recurrence between the two groups, even though it should be noted that the pneumonectomy group had a higher percentage of stage III. Shi therefore declared that sleeve lobectomies should be considered more worthy in patients with earlystage NSCLC. Data on survival at 1, 3 and 5 years, were all in favor of the sleeve resection group. The author reported that only few studies focused on pulmonary function and quality of life, and therefore a meta-analysis of functional outcomes could not be performed (45). Nonetheless, in 2002 Martin-Ucar published an article including 81 pneumonectomies and 38 sleeve lobectomies performed by the same surgeon: the author claimed that lung-sparing resections could be offered to patients without compromising oncological radicality or early outcomes. The spirometry performed 3 months after pulmonary resection showed a loss of $9 \%$ of pre-operative volumes after sleeve lobectomy vs. a loss of $30 \%$ after pneumonectomy (13). In 2008, Balduyck et al. published the results of a prospective study which aimed to focus on functional outcomes and quality of life after bronchial sleeve lobectomy and pneumonectomy. No statistically significant difference in 5 -year survival was observed between the two groups, and no local recurrences occurred in the first 12 months of follow-up. Also, the postoperative complications rate was similar after sleeve resection and pneumonectomy. Patients who underwent sleeve lobectomy reported a negative impact on their physical and social functioning after surgery, but their scores returned approximately to baseline after 1 month. On the other hand, after pneumonectomy there was not a return to baseline values in the 12 months of follow-up (46). In a retrospective study published in 2008, Rea et al. described their 25-year' experience with sleeve resections which included 199 sleeve lobectomies. Interestingly, the Authors found that induction radiotherapy represented a risk factor for perioperative mortality. Locoregional recurrence rate was $11.6 \%$. Overall 5 -year survival 
was $39.7 \%$, while overall 10 -year survival was $28.7 \%$, with no significant difference between stages I-II and stage III. The analysis of survival during the time of the study showed that mortality was significantly lower in the last period, highlighting the importance of overcoming the learning curve of this challenging procedure (47). In 2013, Maurizi et al. reported their experience in an article comparing bronchial and/or vascular sleeve lobectomy with pneumonectomy after induction chemotherapy: no statistically significant differences were found in postoperative mortality, recurrence rate and 3-year survival between the two groups, while patients undergoing lungsparing resection showed a better overall 5 -year survival. Furthermore, when comparing sleeve lobectomies with and without induction therapy, the Authors did not observe significant differences in terms of postoperative complications, postoperative mortality, ICU and hospital stay (48). In time, with the progressively increasing use of VATS technique, surgeons started to perform minimally invasive surgery for sleeve lobectomy too. In an article published in 2013, Li described 11 cases of sleeve lobectomy performed via three-portal VATS: he reported no conversions, and the Authors concluded that this complex procedure can be safely performed using a minimally-invasive approach (31). The first multi-center work regarding VATS sleeve lobectomies was published in 2015 by Huang et al., who reported 13 NSCLC patients undergoing double sleeve lobectomies via multiportal and uniportal VATS, showing the feasibility of this technique for surgeons skilled in VATS and reporting a 0\% 30-day mortality and no signs of recurrence, with a median followup of months (8). A small series of VATS and robotic sleeve resections was also published by Caso et al. in 2018, 6 of those being carried out for NSCLC lesions. Despite the heterogeneity of the procedures reported and the small number of cases, Authors claimed that minimally invasive sleeve resections can be feasible and safe, with perioperative outcomes similar to the ones reported for the open approach, and a shorter length of stay (49).

\section{Discussion}

Sleeve lobectomies were first introduced as an alternative to pneumonectomy in patients with centrally located disease, when pulmonary reserve was thought to be inadequate to tolerate pneumonectomy. Over the subsequent years, different studies showed comparable oncological outcomes to pneumonectomy with lower postoperative mortality and morbidity (17), and it became the procedure of choice for anatomically suitable lesions, regardless of pulmonary function. The advent of VATS approach was in 1992 (50), and in the following years this technique has spread worldwide. Despite the advantages associated with minimally invasive surgery, sleeve lobectomy and bronchoplastic procedures had been viewed for many years as an absolute contraindication to VATS approach, as it is a challenging and technically demanding procedure $(51,52)$. Hansen in 2011 in his relevant paper that standardized the VATS Copenhagen approach, claimed that the minimally invasive procedure was contraindicated in case of disease visible at bronchoscopy (53), as it was considered unsafe; moreover, the surgical community had many doubts about the oncological radicality. The first VATS sleeve procedure was conducted in 2002 for a low-grade mucoepidermoid carcinoma by Santambrogio (6). During the following years, more and more case series were published, demonstrating the feasibility of this approach $(31,54)$. In the last 10 years, the number of reported VATS sleeve resections has exponentially increased, particularly in Asian countries. In 2019, Gao published a retrospective study comparing VATS and thoracotomy sleeve lobectomy using propensity score matching. The number of harvested lymph nodes, as the recurrence rate, both local and distal, was similar between the two groups, while patients in the VATS group showed less blood loss and a shorter hospital length of stay. Moreover, recurrence-free survival and overall survival were better in patients who underwent VATS resection, even though the difference did not reach statistical significance. Gao therefore claimed that VATS sleeve lobectomy was a safe procedure, with oncological outcomes comparable to those after thoracotomy sleeve lobectomy and a faster postoperative recovery (55). It should also be considered that the more rapid healing after VATS surgery could lead to an earlier start of adjuvant chemotherapy, which in these cases is often indicated (56). Currently, the reported average operating time of a VATS procedure is significantly longer, compared with patients who undergo sleeve lobectomy by thoracotomy approach (57), but with increasing experience in VATS procedures this difference will progressively decrease. In expert hands, the centrality of a tumor, invading hilar structures, is not considered an absolute contraindication to a minimally invasive approach by most surgeons, even by uniportal technique (58). Moreover, the advancement of dedicated technology development, such as 3D cameras, is considered very promising in this field, because a better visualization will allow a straightforward bronchial suture. In conclusion, if oncological criteria are observed, patients with 
centrally located disease can benefit from the mini-invasive VATS approach, in high-experienced centers.

\section{Acknowledgments}

Funding: None.

\section{Footnote}

Provenance and Peer Review: This article was commissioned by the Guest Editors (Francesco Zaraca, Reinhold Perkmann, Luca Bertolaccini and Roberto Crisci) for the series "Thoracic Surgery Without Borders" published in Current Challenges in Thoracic Surgery. The article has undergone external peer review.

Conflicts of Interest: All authors have completed the ICMJE uniform disclosure form (available at https://ccts. amegroups.com/article/view/10.21037/ccts.2019.12.10/ coif). The series "Thoracic Surgery Without Borders" was commissioned by the editorial office without any funding or sponsorship. DT serves as an unpaid editorial board member of Current Challenges in Thoracic Surgery from November 2019 to October 2021. The authors have no other conflicts of interest to declare.

Ethical Statement: The authors are accountable for all aspects of the work in ensuring that questions related to the accuracy or integrity of any part of the work are appropriately investigated and resolved.

Open Access Statement: This is an Open Access article distributed in accordance with the Creative Commons Attribution-NonCommercial-NoDerivs 4.0 International License (CC BY-NC-ND 4.0), which permits the noncommercial replication and distribution of the article with the strict proviso that no changes or edits are made and the original work is properly cited (including links to both the formal publication through the relevant DOI and the license). See: https://creativecommons.org/licenses/by-nc-nd/4.0/.

\section{References}

1. Thomas CP. Conservative resection of the bronchial tree. J R Coll Surg Edinb 1956;1:169-86.

2. Allison PR. Personal communication. Quoted by Johnston JB, Jones PH. The treatment of bronchial carcinoma by lobectomy and sleeve resection of the main bronchus.
Thorax 1959;14:48-54.

3. Abbott OA. Experiences with the surgical resection of the human carina, tracheal wall, and contralateral bronchial wall in cases of right total pneumonectomy. J Thorac Surg 1950;19:906-22.

4. Chamberlain JM, Mc Neill TM, Parnassa P, et al. Bronchogenic carcinoma: an aggressive surgical attitude. J Thorac Cardiovasc Surg 1959;38:727-45.

5. Grillo HC. Carinal reconstruction. Ann Thorac Surg 1982;34:356-73.

6. Santambrogio L, Cioffi U, De Simone M, et al. Videoassisted sleeve lobectomy for mucoepidermoid carcinoma of the left lower lobar bronchus: a case report. Chest 2002;121:635-6.

7. Gonzalez-Rivas D, Fernandez R, Fieira E, et al. Uniportal video-assisted thoracoscopic bronchial sleeve lobectomy first report. J Thorac Cardiovasc Surg 2013;145:1676-7.

8. Huang J, Li J, Qiu Y, et al. Thoracoscopic double sleeve lobectomy in 13 patients: A series report form multicenters. J Thorac Dis 2015;7:834-42.

9. Gonzalez-Rivas D, Delgado M, Fieira E, et al. Double sleeve uniportal video-assisted thoracoscopic lobectomy for non-small cell lung cancer. Ann Cardiothorac Surg 2014;3:E2.

10. Gonzalez-Rivas D, Yang Y, Stupnik T, et al. Uniportal video-assisted thoracoscopic bronchovascular, tracheal and carinal sleeve resections†. Eur J Cardiothorac Surg 2016;49 Suppl 1:i6-16.

11. Cerfolio RJ, Deschamps C, Allen MS, et al. Mainstem bronchial sleeve resection with pulmonary preservation. Ann Thorac Surg 1996;61:1458-62; discussion 1462-3.

12. Ma QL, Guo YQ, Shi B, et al. For non-small cell lung cancer with T3 (central) disease, sleeve lobectomy or pneumonectomy? J Thorac Dis 2016;8:1227-33.

13. Martin-Ucar AE, Chaudhuri N, Edwards JG, et al. Can pneumonectomy for non-small cell lung cancer be avoided? An audit of parenchymal sparing lung surgery. Eur J Cardiothorac Surg 2002;21:601-5.

14. Rendina EA, Venuta F, de Giacomo T, et al. Parenchymal sparing operations for bronchogenic carcinoma. Surg Clin North Am 2002;82:589-609.

15. Beauchamp G. Fundamentals of standard sleeve resection. Thorac Surg Clin 2018;28:285-9.

16. Tronc F. Bronchoplasty. In: Patterson G, Cooper J, Deslauriers J, et al. editors. Pearson's thoracic \& esophageal surgery. 3rd ed. Philadelphia: Churchill Livingstone Elsevier, 2008:894-908.

17. Tronc F, Gregoire J, Deslauriers J. Long term results of 
sleeve lobectomy for lung cancer. Eur J Cardiothorac Surg 2000;17:550-6.

18. Mentzer SJ. Right upper lobe sleeve resection. Operative Techniques in Thoracic and Cardiovascular Surg 1998:3:166-77.

19. Merritt RE, Mathisen DJ, Wain JC, et al. Long-term results of sleeve lobectomy in the management of nonsmall cell lung carcinoma and low-grade neoplasms. Ann Thorac Surg 2009;88:1574-81; discussion 1581-2.

20. Fadel E, Yildizeli B, Chapelier AR, et al. Sleeve lobectomy for bronchogenic cancers: factors affecting survival. Ann Thorac Surg 2002;74:851-8; discussion 858-9.

21. D'Andrilli A, Maurizi G, Andreetti C, et al. Sleeve lobectomy versus standard lobectomy for lung cancer: functional and oncologic evaluation. Ann Thorac Surg 2016;101:1936-42.

22. Davoli F, Bertolaccini L, Pardolesi A, et al. Video-assisted thoracoscopic surgery bronchial sleeve lobectomy. J Vis Surg 2017;3:41.

23. Predina JD, Kunkala M, Aliperti LA, et al. Sleeve lobectomy: current indications and future directions. Ann Thorac Cardiovasc Surg 2010;16:310-8.

24. Gonzalez M, Litzistorf Y, Krueger T, et al. Impact of induction therapy on airway complications after sleeve lobectomy for lung cancer. Ann Thorac Surg 2013;96:247-52.

25. Gómez-Caro A, Boada M, Reguart N, et al. Sleeve lobectomy after induction chemoradiotherapy. Eur J Cardiothorac Surg 2012;41:1052-8.

26. Kim YT, Kang CH, Sung SW, et al. Local control of disease related to lymph node involvement in non-small cell lung cancer after sleeve lobectomy compared with pneumonectomy. Ann Thorac Surg 2005;79:1153-61.

27. Terzi A, Lonardoni A, Falezza G, et al. Sleeve lobectomy for non-small cell lung cancer and carcinoids: results in 160 cases. Eur J Cardiothorac Surg 2002;21:888-93.

28. Mehran RJ, Deslauriers J, Piraux M, et al. Survival related to nodal status after sleeve resection for lung cancer. J Thorac Cardiovasc Surg 1994;107:576-82; discussion 582-3.

29. Ludwig C, Stoelben E, Olschewski M, et al. Comparison of morbidity, 30-day mortality, and long-term survival after pneumonectomy and sleeve lobectomy for non-small cell lung carcinoma. Ann Thorac Surg 2005;79:968-73.

30. Shao W, Phan K, Guo X, et al. Non-intubated complete thoracoscopic bronchial sleeve resection for central lung cancer. J Thorac Dis 2014;6:1485-8.

31. Li Y, Wang J. Video-assisted thoracoscopic surgery sleeve lobectomy with bronchoplasty. World J Surg 2013;37:1661-5.

32. Okada M, Tsubota N, Yoshimura M, et al. Extended sleeve lobectomy for lung cancer: the avoidance of pneumonectomy. J Thorac Cardiovasc Surg 1999;118: 710-3; discussion 713-4.

33. Frist WH, Mathisen DJ, Hilgenberg AD, et al. Bronchial sleeve resection with and without pulmonary resection. J Thorac Cardiovasc Surg 1987;93:350-7.

34. Chen H, Huang L, Xu G, et al. Modified bronchial anastomosis in video-assisted thoracoscopic sleeve lobectomy: a report of 32 cases. J Thorac Dis 2016;8:2233-40.

35. Zhang Z, Huang Q, Liao Y, et al. Application of the "continuous suture dividing and equal suture tightening" method in video-assisted thoracoscopic surgery sleeve lobectomy. J Thorac Dis 2018;10:5199-207.

36. Jiang WY, Liao YD, Cai YX, et al. Application of pedicled aortic adventitia flap in the reinforcement of bronchial stump or bronchial anastomotic stoma closure in left pulmonary resection. J Thorac Cardiovasc Surg 2014;148:351-3.

37. Tosi D, Mohamed S, Pieropan S, et al. Intercostal muscle flap to reinforce the bronchial stump after video-assisted thoracic surgery pneumonectomy. Curr Chall Thorac Surg 2019;1:14.

38. Berthet JP, Paradela M, Jimenez MJ, et al. Extended sleeve lobectomy: one more step toward avoiding pneumonectomy in centrally located lung cancer. Ann Thorac Surg 2013;96:1988-97.

39. Toyooka S, Soh J, Yamamoto H, et al. Extended sleeve lobectomy after induction chemoradiotherapy for nonsmall cell lung cancer. Surg Today 2015;45:1121-6.

40. Yamamoto K, Miyamoto Y, Ohsumi A, et al. Sleeve lung resection for lung cancer: analysis according to the type of procedure. J Thorac Cardiovasc Surg 2008;136:1349-56.

41. Chida M, Minowa M, Miyoshi S, et al. Extended sleeve lobectomy for locally advanced lung cancer. Ann Thorac Surg 2009;87:900-5.

42. Okada M, Yamagishi H, Satake S, et al. Survival related to lymph node involvement in lung cancer after sleeve lobectomy compared with pneumonectomy. J Thorac Cardiovasc Surg 2000;119:814-9.

43. Park JS, Yang HC, Kim HK, et al. Sleeve lobectomy as an alternative procedure to pneumonectomy for non-small cell lung cancer. J Thorac Oncol 2010;5:517-20.

44. Pagès PB, Mordant P, Renaud S, et al. Sleeve lobectomy may provide better outcomes than pneumonectomy for 
non-small cell lung cancer. A decade in a nationwide study. J Thorac Cardiovasc Surg 2017;153:184-95.e3.

45. Shi $W$, Zhang $W$, Sun $H$, et al. Sleeve lobectomy versus pneumonectomy for non-small cell lung cancer: a metaanalysis. World J Surg Oncol 2012;10:265.

46. Balduyck B, Hendriks J, Lauwers P, et al. Quality of life after lung cancer surgery: a prospective pilot study comparing bronchial sleeve lobectomy with pneumonectomy. J Thorac Oncol 2008;3:604-8.

47. Rea F, Marulli G, Schiavon M, et al. A quarter of a century experience with sleeve lobectomy for non-small cell lung cancer. Eur J Cardiothorac Surg 2008;34:488-92; discussion 492.

48. Maurizi G, D’Andrilli A, Anile M, et al. Sleeve lobectomy compared with pneumonectomy after induction therapy for non-small-cell lung cancer. J Thorac Oncol 2013;8:637-43.

49. Caso R, Watson TJ, Khaitan PG, et al. Outcomes of minimally invasive sleeve resection. J Thorac Dis 2018;10:6653-9.

50. Roviaro G, Rebuffat C, Varoli F, et al. Videoendoscopic pulmonary lobectomy for cancer. Surg Laparosc Endosc 1992;2:244-7.

51. Demmy TL, James TA, Swanson SJ, et al. Troubleshooting video-assisted thoracic surgery lobectomy. Ann Thorac Surg 2005;79:1744-52; discussion 1753.

52. McKenna RJ Jr, Houck W, Fuller CB. Video-assisted

doi: $10.21037 /$ ccts.2019.12.10

Cite this article as: Tosi D, Musso V, Damarco F, Mohamed S, Mazzucco A, Cattaneo M, Daffrè E, Diotti C, Pieropan S, Nosotti M. Sleeve video-assisted thoracic surgery resections. Curr Chall Thorac Surg 2020;2:18. thoracic surgery lobectomy: experience with 1,100 cases. Ann Thorac Surg 2006;81:421-5; discussion 425-6.

53. Hansen HJ, Petersen RH, Christensen M. Videoassisted thoracoscopic surgery (VATS) lobectomy using a standardized anterior approach. Surg Endosc 2011;25:1263-9.

54. Mahtabifard A, Fuller CB, McKenna RJ Jr. Video-assisted thoracic surgery sleeve lobectomy: a case series. Ann Thorac Surg 2008;85:S729-32.

55. Gao HJ, Jiang ZH, Gong L. Video-assisted vs thoracotomy sleeve lobectomy for lung cancer: a propensity matched analysis. Ann Thorac Surg 2019;108:1072-9.

56. Teh E, Abah U, Church D, et al. What is the extent of the advantage of video-assisted thoracoscopic surgical resection over thoracotomy in terms of delivery of adjuvant chemotherapy following non-small-cell lung cancer resection? Interact Cardiovasc Thorac Surg 2014;19:656-60.

57. Zhou S, Pei G, Han Y, et al. Sleeve lobectomy by videoassisted thoracic surgery versus thoracotomy for non-small cell lung cancer. J Cardiothorac Surg 2015;10:116.

58. Bertolaccini L, Batirel H, Brunelli A, et al. Uniportal video-assisted thoracic surgery lobectomy: a consensus report from the Uniportal VATS Interest Group (UVIG) of the European Society of Thoracic Surgeons (ESTS). Eur J Cardiothorac Surg 2019;56:224-9. 